NASA/TM—2007-214942

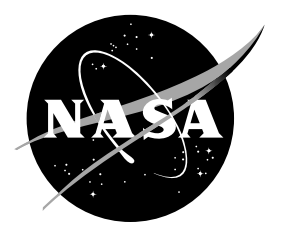

\title{
Unsteady Turbine Blade and Tip Heat Transfer Due to Wake Passing
}

Ali A. Ameri

The Ohio State University, Columbus, Ohio

David L. Rigby

Glenn Research Center, Cleveland, Ohio

Erlendur Steinthorsson

$A \& E$ Consulting, Westlake, Ohio

James Heidmann and John C. Fabian

Glenn Research Center, Cleveland, Ohio 


\section{NASA STI Program . . . in Profile}

Since its founding, NASA has been dedicated to the advancement of aeronautics and space science. The NASA Scientific and Technical Information (STI) program plays a key part in helping NASA maintain this important role.

The NASA STI Program operates under the auspices of the Agency Chief Information Officer. It collects, organizes, provides for archiving, and disseminates NASA's STI. The NASA STI program provides access to the NASA Aeronautics and Space Database and its public interface, the NASA Technical Reports Server, thus providing one of the largest collections of aeronautical and space science STI in the world. Results are published in both non-NASA channels and by NASA in the NASA STI Report Series, which includes the following report types:

- TECHNICAL PUBLICATION. Reports of completed research or a major significant phase of research that present the results of NASA programs and include extensive data or theoretical analysis. Includes compilations of significant scientific and technical data and information deemed to be of continuing reference value. NASA counterpart of peer-reviewed formal professional papers but has less stringent limitations on manuscript length and extent of graphic presentations.

- TECHNICAL MEMORANDUM. Scientific and technical findings that are preliminary or of specialized interest, e.g., quick release reports, working papers, and bibliographies that contain minimal annotation. Does not contain extensive analysis.

- CONTRACTOR REPORT. Scientific and technical findings by NASA-sponsored contractors and grantees.
- CONFERENCE PUBLICATION. Collected papers from scientific and technical conferences, symposia, seminars, or other meetings sponsored or cosponsored by NASA.

- SPECIAL PUBLICATION. Scientific, technical, or historical information from NASA programs, projects, and missions, often concerned with subjects having substantial public interest.

- TECHNICAL TRANSLATION. Englishlanguage translations of foreign scientific and technical material pertinent to NASA's mission.

Specialized services also include creating custom thesauri, building customized databases, organizing and publishing research results.

For more information about the NASA STI program, see the following:

- Access the NASA STI program home page at http://www.sti.nasa.gov

- E-mail your question via the Internet to help@sti.nasa.gov

- Fax your question to the NASA STI Help Desk at 301-621-0134

- Telephone the NASA STI Help Desk at 301-621-0390

- Write to: NASA Center for AeroSpace Information (CASI) 7115 Standard Drive Hanover, MD 21076-1320 
NASA/TM—2007-214942

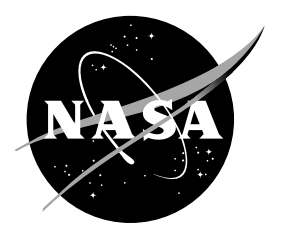

\section{Unsteady Turbine Blade and Tip Heat Transfer Due to Wake Passing}

Ali A. Ameri

The Ohio State University, Columbus, Ohio

David L. Rigby

Glenn Research Center, Cleveland, Ohio

Erlendur Steinthorsson

$A \&$ E Consulting, Westlake, Ohio

James Heidmann and John C. Fabian

Glenn Research Center, Cleveland, Ohio

Prepared for

Turbo Expo 2007

sponsored by the American Society of Mechanical Engineers and the International Gas Turbine Institute Montreal, Canada, May 14-17, 2007

National Aeronautics and

Space Administration

Glenn Research Center

Cleveland, Ohio 44135 
This work was sponsored by the Fundamental Aeronautics Program at the NASA Glenn Research Center.

Level of Review: This material has been technically reviewed by technical management.

Available from

NASA Center for Aerospace Information 7115 Standard Drive

Hanover, MD 21076-1320
National Technical Information Service 5285 Port Royal Road Springfield, VA 22161

Available electronically at http://gltrs.grc.nasa.gov 


\title{
Unsteady Turbine Blade and Tip Heat Transfer Due to Wake Passing
}

\author{
Ali A. Ameri \\ The Ohio State University \\ Columbus, Ohio 43210 \\ David L. Rigby \\ ASRC Aerospace Corporation \\ Glenn Research Center \\ Cleveland, Ohio 44135 \\ Erlendur Steinthorsson \\ A \& E Consulting \\ Westlake, Ohio 44140 \\ James Heidmann and John C. Fabian \\ National Aeronautics and Space Administration \\ Glenn Research Center \\ Cleveland, Ohio 44135
}

\section{ABSTRACT}

The geometry and the flow conditions of the first stage turbine blade of GE's $E^{3}$ engine have been used to obtain the unsteady three-dimensional blade and tip heat transfer. The isothermal wall boundary condition was used. The effect of the upstream wake of the first stage vane was of interest and was simulated by provision of a "gust" type boundary condition upstream of the blades. A one blade periodic domain was used. The consequence of this choice was explored in a preliminary study which showed little difference in the time mean heat transfer between a 1:1 and 2:3 vane/blade domains. The full threedimensional computations are of the blade having a clearance gap of $2 \%$ the span. Comparison between the time averaged unsteady and steady heat transfer is provided. It is shown that there is a significant difference between the steady and time mean of unsteady blade heat transfer in localized regions. The differences on the suction side of the blade in the near hub and near tip regions were found to be rather significant. Steady analysis underestimated the blade heat transfer by as much as $20 \%$ as compared to the time average obtained from the unsteady analysis. As for the blade tip, the steady analysis and the unsteady analysis gave results to within two percent.

\section{NOMENCLATURE}

C axial Chord

h heat transfer coefficient $=\mathrm{q}_{\mathrm{w}} /\left(\mathrm{T}_{\mathrm{o}}-\mathrm{T}_{\mathrm{w}}\right)$

$\mathrm{K}$ reference thermal conductivity

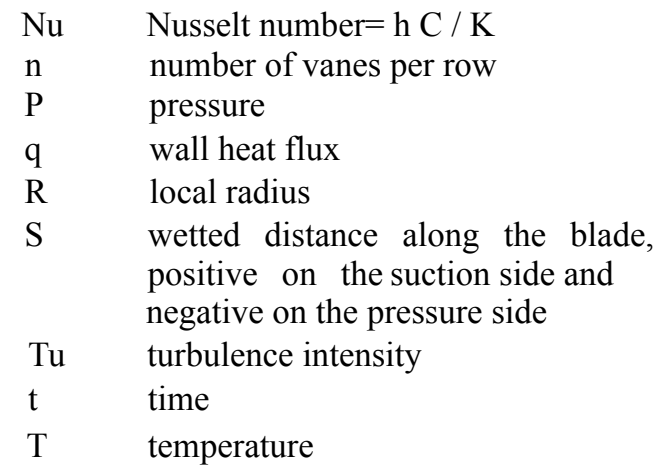

Greek

$\theta \quad$ local tangential angle

$\tau \quad$ time period for one wake passage 


\section{INTRODUCTION}

There has been interest in the study of unsteady aerodynamics and heat transfer as related to turbine blades. This is attested to by the number of articles which have appeared in the literature. The desire to obtain a complete unsteady flow and heat transfer solution in turbine passages is tempered when consideration is given to the enormity of the resources required. As the computational capabilities grow, obtaining unsteady solutions using turbulence closure models become more realistic and indeed URANS (Unsteady Reynolds Averaged Navier-Stokes) solutions are becoming common. Unsteady RANS calculations including the rotor/stator interaction have also been performed to predict unsteady heat transfer on blades and vanes. Such work would include the work of Rao et al.[1] who used a 2 to 3 vane to stator blade count and a 2-d code to simulate the unsteady pressure and heat transfer. In fact the experimental work, which was carried further to different vane/blade spacings, reported by Dunn et al. [2] was specifically designed with 45 rotor blades and 30 stator blades to provide a data base for numerical verification. Most turbine data come from rigs which are not as forgiving to CFD methods. The work of Michelassi et al.[3] is a case in point in which the authors rescaled the blade to maintain a one to one ratio of the vaneblade count and used a 3-d methodology to calculate the blade heat transfer. Abhari et al. [4] used the 2-d code UNSFLO which uses a transformed Euler scheme to accommodate the vane to blade count ratio to compute the rotor stator interaction in a quasi-3d manner. The viscous layer was computed using a thin layer approximation and an algebraic turbulence model was used. Dunn et al. [2] studied the effect of vane/blade spacing on both the vane and blade for three different spacings. The study was performed for the mid span. They measured the unsteady heat flux and computed the same using a 2-d computer program UNSFLO.

In an earlier paper Ameri et al.[5] used a simple analysis to determine the effect of wake unsteadiness on a 'sliver' of the blade without accounting for the three dimensional effects. In [5], no appreciable difference between the time-averaged blade heat transfer and the blade heat transfer obtained using a steady analysis was found. It was also found that quasi-steady analysis of the blade without the effect of rotation leads to erroneous results with respect to the unsteady envelope of heat transfer. This conclusion is particularly pertinent to experimental measurements of blade heat transfer attempting to estimate the unsteady variation by accounting for the relative position of the stator in relation to the rotor without accounting for the relative rotational speed. It was also found, surprisingly, that the average thus computed did not differ appreciably from the time mean or steady values.

In this paper we mainly address the issue of unsteady heat transfer in high pressure turbine blades as related to passing of upstream wakes. The conditions considered here are chosen to be simple. Namely, the wake is chosen to have a deficit in total pressure and possess a wake-like profile of turbulence intensity and length scale. The variation in total temperature typical of cooled vanes has been deliberately set aside to enable separation of the various effects. The total temperature variation is one effect that we hope to visit in the near future. In the absence of film cooling, the high cycle unsteady variations in heat transfer as manifested by traveling waves of peaks and valleys typically have frequencies that are too large to have any appreciable penetration depth on the blade. In this paper a numerical experiment is presented that compares the time mean pressure and heat transfer computed with an unsteady analysis method against computations of pressure and heat transfer using the simpler steady analysis. The difference will reveal the error incurred by not taking the unsteadiness into account by means of an unsteady RANS computation.

The paper will discuss, in order, the numerical scheme, a two-dimensional preliminary study which focuses on the validity of the one blade periodicity assumption, and the presentation and discussion of the $3 \mathrm{D}$ analysis.

\section{COMPUTATIONAL STUDY}

The computer code used for this study was GlennHT2000. This computer code was written using object oriented programming principles and the Fortran90 programming language. The numerical procedure uses a finite-volume discretization scheme that is second order accurate in time and space. An implicit time marching scheme is implemented using subiterations. The turbulence model used for the calculations was the Low Reynolds number k- $\omega$ model of Wilcox[6] which integrates to the walls (i.e., without the use of wall-functions). The grid used was quite fine adjacent to the blade (maximum value of $y^{+}<1$ ) in the boundary layer. The turbulence model is able to produce an effect similar to the transition from laminar to turbulent flow. In practice, however, the transition is not guaranteed to be in the appropriate location. In fact it is often triggered very near the leading edge which is what occurred in our computations making them turbulent except near the stagnation line. Further details about the code may be found in Ameri et al. [7]. The present version of the computer code is fully parallelized and uses MPI (Message Passing Interface) for parallel processing. The three-dimensional cases were run on 48 processors of a 98 processor Xeon Linux Cluster.

\section{THE CASE CONSIDERED}

The geometry and the flow conditions of the first stage turbine blade of GE's $\mathrm{E}^{3}$ engine [8] have been used to obtain the unsteady three-dimensional blade and tip heat transfer. The blade was rotating at 8400 RPM. The pressure ratio across the rotor blade based on the stage total pressure was 2.27. There were 76 blades and 46 vanes or a blade-vane ratio of 1.65 . The tip clearance was $2 \%$ of the blade span. The case was previously computed in [7] and [9]. The numerical scheme has been experimentally validated for tip heat transfer computations in [10] and [11].

The effect of the upstream wake of the first stage vane on the blade heat transfer and pressure was simulated by provision of a "gust" type boundary condition upstream of the blades. A three-dimensional RANS calculation was done to obtain the predicted heat transfer on the rotor blade. The guide vane flow was calculated using the same code in steady mode. The total pressure in the wake thus produced was fitted with a trigonometric function and placed as the boundary condition at the inlet of the rotor as, 


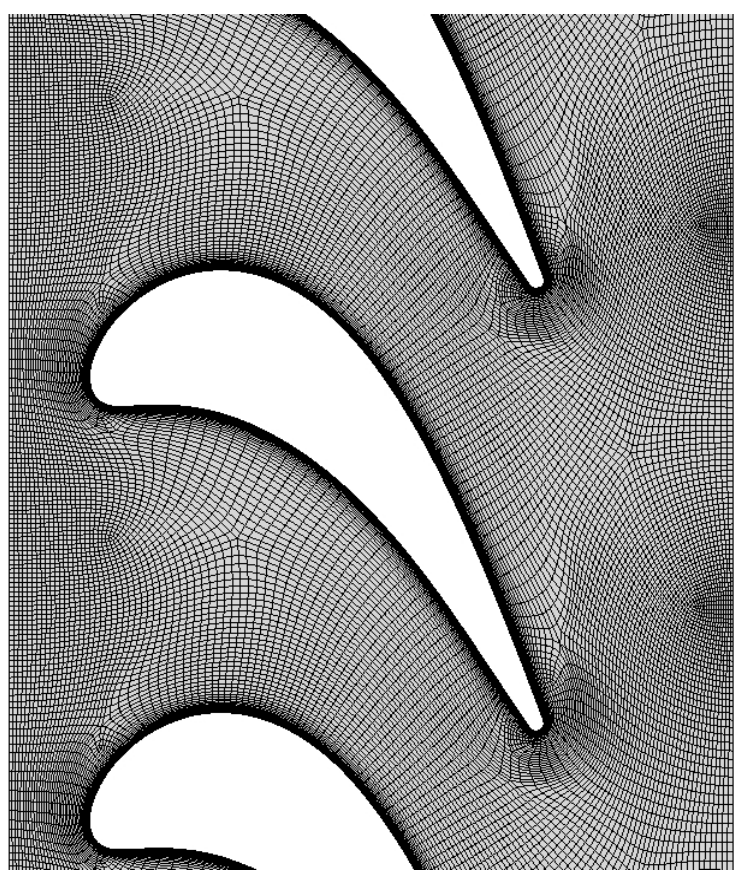

Figure 1- Blade profile and the computational grid

$$
\mathrm{P}_{0}(\mathrm{t}, \theta)=\mathrm{P}_{0-\mathrm{bg}}\left\{1 .-0.15[\operatorname{Sin}(\mathrm{n} \theta / 2+\pi \mathrm{t} / \tau)]^{10}\right\}
$$

Where the subscript of bg designates the background value which is a function of radial position only. The wake turbulence and length scale were also fitted with trigonometric functions and specified at the inlet. The background level for turbulence intensity was $2 \%$ and the amplitude was $3 \%$ for a peak value of $5 \%$, i.e.,

$$
\mathrm{Tu}(\mathrm{t}, \theta)=\mathrm{Tu}_{\mathrm{bg}}+\mathrm{Tu}_{\mathrm{amp}}[\operatorname{Sin}(\mathrm{n} \theta / 2+\pi \mathrm{t} / \tau)]^{6 .}
$$

The same applies to the length scale with a background level of $.01 * \mathrm{Cx}$ and a peak of $.025^{*} \mathrm{Cx}$. The average inlet turbulence was computed to be $2.6 \%$ with an average length scale of .015 $\mathrm{Cx}$. It should be noted the turbulence intensity as specified at the inlet is a fraction of absolute free stream velocity. As a fraction of the relative velocity, the average inlet turbulence level is about $7 \%$. This is because, at the midspan, the inlet absolute velocity approaches the blade at 75 degrees and the relative velocity's approach is at approximately 45 thus yielding 2.7 as the ratio of the absolute velocity to the relative velocity.

To reduce the cost of the computations, a wake passing frequency corresponding to a one to one vane blade ratio was used. A study was made to explore the consequences of this simplification. This preliminary calculation is presented first.

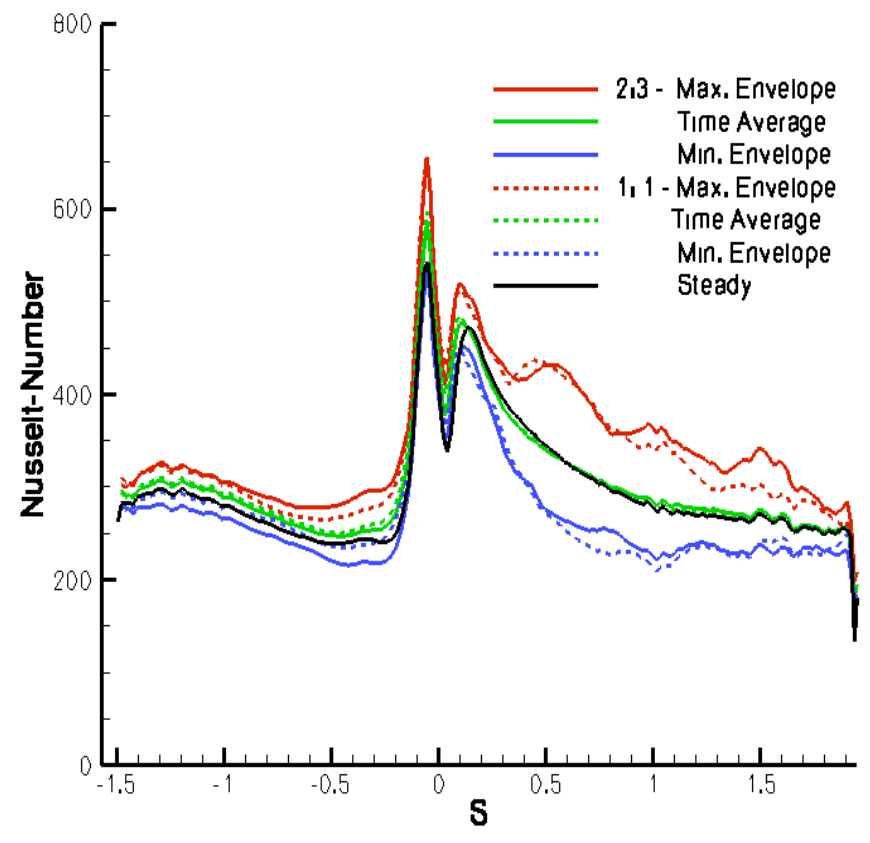

Figure 2- Effect of wake passing frequency on blade heat transfer

\section{PRELIMINARY EVALUATION}

To determine the consequences of the simplification discussed above, namely, equal ratio of the number of vanes to rotors, the following preliminary study was done. A three passage 'sliver' in the mid span area was chosen for which the heat transfer calculation was performed. The grid, shown in Fig. 1, had four cells in the radial direction which covered a small radial distance. Slip boundary conditions were used on the two radial surfaces. The computations were for exploratory purposes and thus no corrections for stream tube thickness were made. The three passages were subjected to gust boundary condition corresponding to two upstream vanes approximately having the correct blade vane ratio of 1.5 and three upstream vanes corresponding to a one to one ratio. Computations were made on the same three blade passage grid. This was done to remove the grid resolution as a confounding effect. The results are shown in Fig 2. Figure 2 has, on the abscissa, the wetted distance along the blade midspan. The distance is measured from the minimum axial location on the blade and is positive in the direction of the suction side and negative in the direction of the pressure side. The ordinate is the Nusselt number $(\mathrm{Nu})$ based on the axial chord which is a measure of wall heat flux. As shown, the wake passing frequency has a small effect on average heat transfer on the blade for the chosen frequencies. There is a very small difference on the pressure side and still smaller on the suction side. The difference from the steady values is also quite small. The envelope on the same Fig. 2 shows that the lower frequency leads to larger amplitude. This effect is more pronounced on the pressure side. The higher wake passing frequency to be presented is thus expected to produce smaller amplitude variation in unsteady heat transfer 


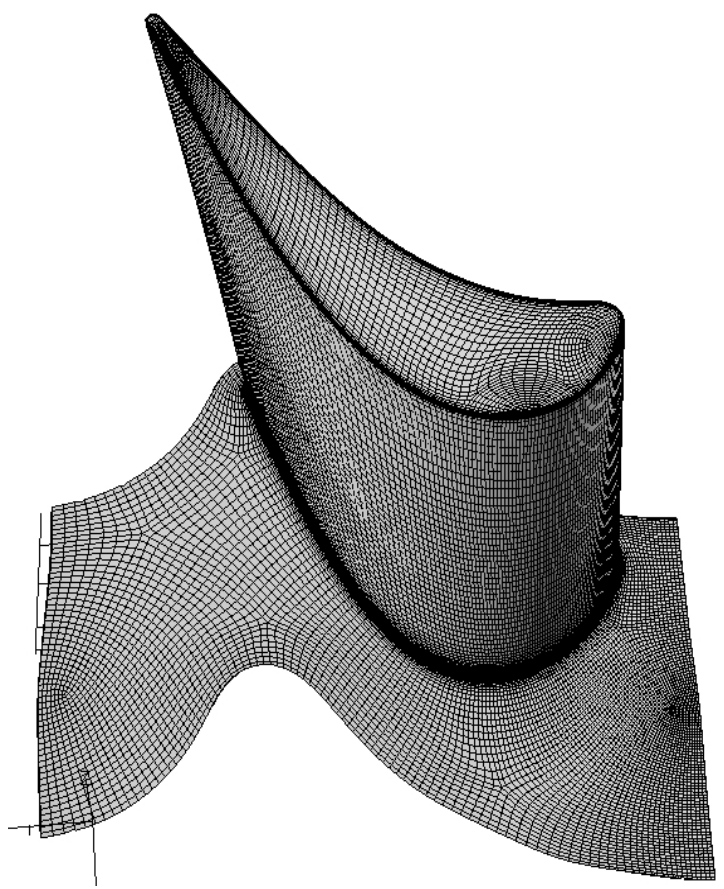

Figure 3- Grid

but with an average heat transfer that is a good representation of the correct frequency. The steady results shown in Fig. 2 were obtained by ensuring that the inlet total pressure prescribed at the upstream inlet of the computational domain was equal to the average inlet total pressure for the unsteady cases.

\section{UNSTEADY NEAR-TIP FLOW}

Figure 3 is the grid used for the three dimensional computations performed in this work. The grid contained 164 blocks and had a total of 1.8 million nodes. There are 65 nodes across the tip gap in the radial direction. The grid density from the hub to the tip was 101 nodes. An unstructured grid topology with individual structured blocks was used. This offers the flexibility of refining the grid locally as needed without unduly refining the grid in areas where such refinement is unnecessary. The grid density was arrived at after running exploratory computations similar to those already mentioned in the last section. The grid was deemed sufficiently refined when able to support a wake without it dissipating. A dimensionless time step of .005 was used after comparing results using time steps of $0.001,0.0025,0.005$ and 0.01 . The results showed that the time histories for the first three time steps were identical, while the larger 0.01 deviated from that time history. The larger time step of 0.005 also resulted in fewer total subiterations and faster convergence. For this time step there were 320 time steps required to cover the passing of a wake across a single blade passage. The computations were performed assuming isothermal wall condition of 0.7 times the stage inlet total temperature. This condition was applied to all the walls, including the hub, the blade, the blade tip and the case. The rate

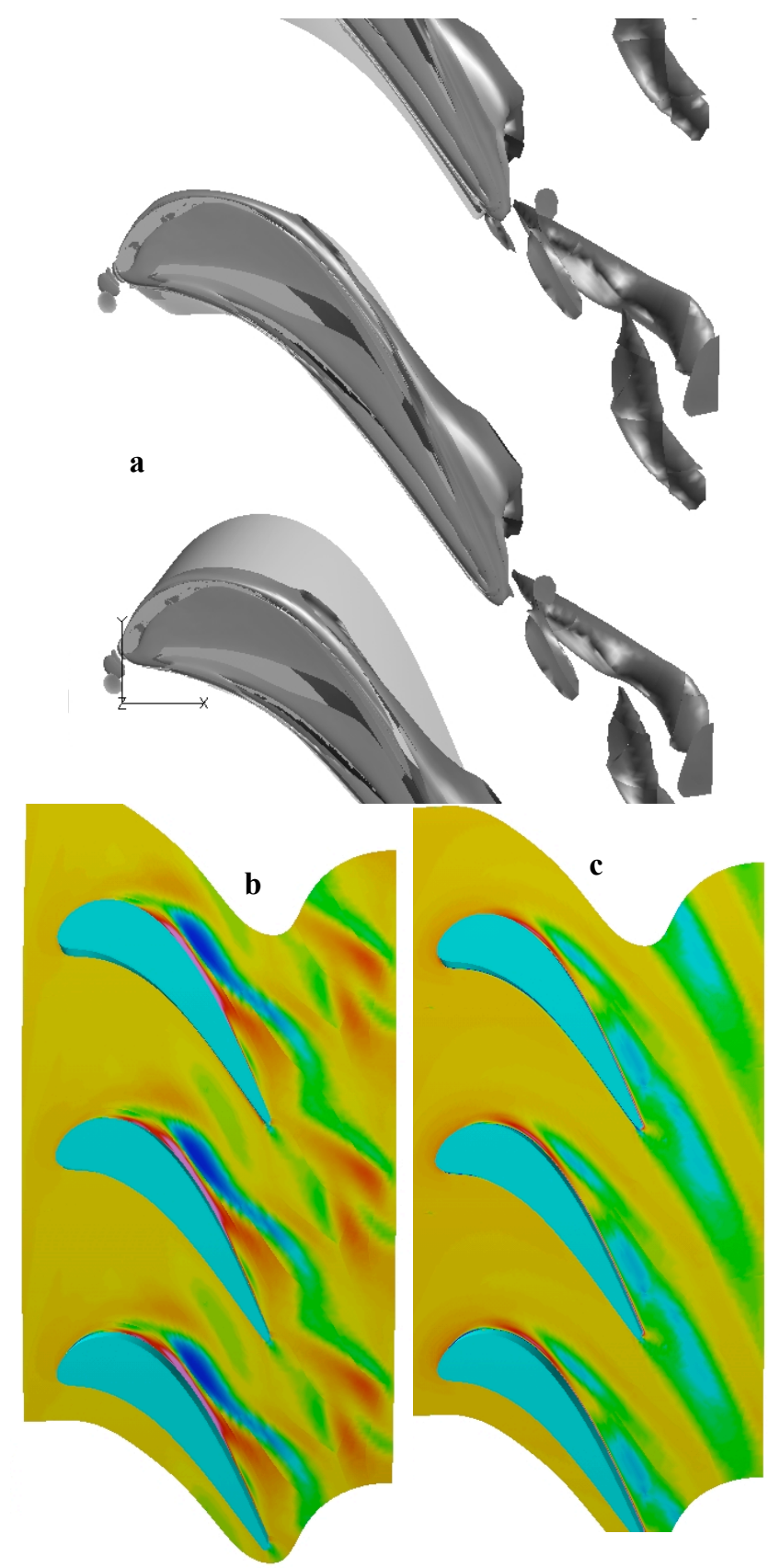

Figure 4- (a) Iso-surface of helicity magnitude, and helicity plot at a radius near the tip for (b) unsteady and (c) steady flow

of heat transfer as a function of time was computed for all the cooled surfaces.

Figure $4 \mathrm{a}$ is an iso-surface plot of the magnitude of the helicity which is defined as dot product of the vorticity and velocity vector. A plot of this quantity allows for flow visualization and facilitates detection of flow patterns. The isosurface of helicity shows the shedding of vortical structures from the trailing edge of the blade for the unsteady simulation. 


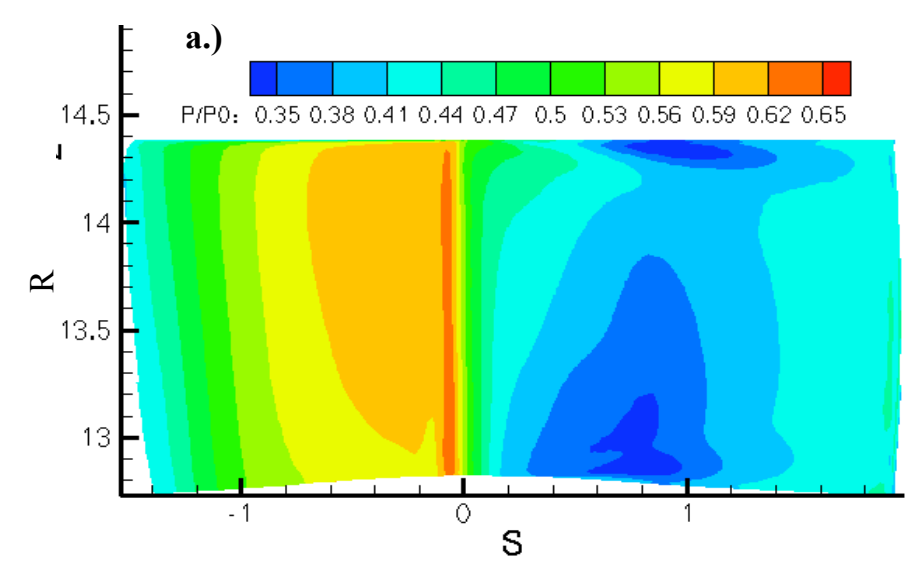

b.)

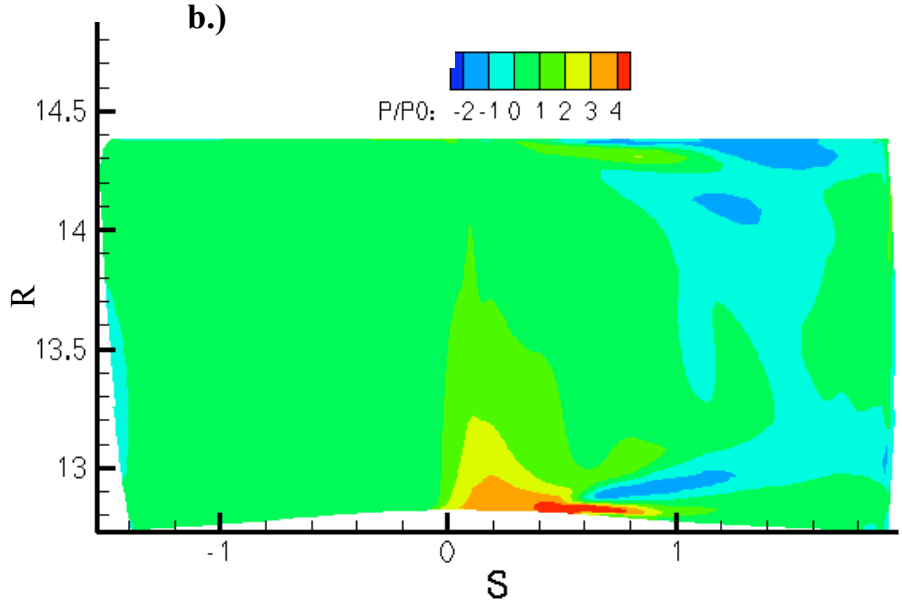

Figure 5- (a) Steady pressure distribution over the blade surface and (b) percent deviation of the time averaged pressure from the steady solution

These vortical structures are generated from the accumulation of the tip leakage flow on the suction side and subsequent "wiping off" by the passing of wake flow through the passage. The periodic occurrence of this event gives rise to the structure shown in figure $4 \mathrm{a}$. The flow structure is completely generated in the tip region and on the suction side. Figure $4 \mathrm{~b}$ is a snapshot of the unsteady computation showing the helicity on a constant radius surface near the tip. Fig. $4 \mathrm{c}$ shows the same quantity when the computation is performed as a steady flow.

\section{HEAT TRANSFER AND PRESSURE DISTRIBUTION}

In this section of the paper, pressure and heat transfer distributions over the blade surface and the blade tip are presented. Instead of presenting the unsteady variations, we have mostly focused our presentation on the discussion of the time-averaged values and the difference of these quantities from those derived from a steady computation.

The intention of this exercise is to discover and highlight the differences between the pressure and heat transfer obtained using an unsteady computation as compared to a steady computation. No inlet total temperature variation (hot streak) is involved except for the thermal boundary layer prescribed at the hub and casing ends of the inlet. This task is accomplished by careful computations of the unsteady and steady flows with consistent boundary conditions for the steady and unsteady cases. For the unsteady computation, the wake profile for quantities of total pressure and turbulence were prescribed at the inlet. This was already described under the title "The Case Considered". For the steady computation the inlet conditions for the unsteady computations were integrated over the inlet and specified at the inlet. The average inlet turbulence was computed to be $2.6 \%$ with a length scale of $.015 \mathrm{Cx}$. The specification of the proper "steady equivalent" boundary conditions is important if the comparison between the steady and unsteady computations is to be meaningful.

\section{BLADE SURFACE}

\section{Pressure Distribution}

Figure 5 shows the pressure distribution as determined by the steady calculation (Fig. 5a) and the percent departure from the steady pressure of the time-mean value over the blade (Fig. $5 b)$. It can be argued that, for the case considered, the steady computation does provide a pressure distribution which is close to the time mean results and is sufficient for engineering

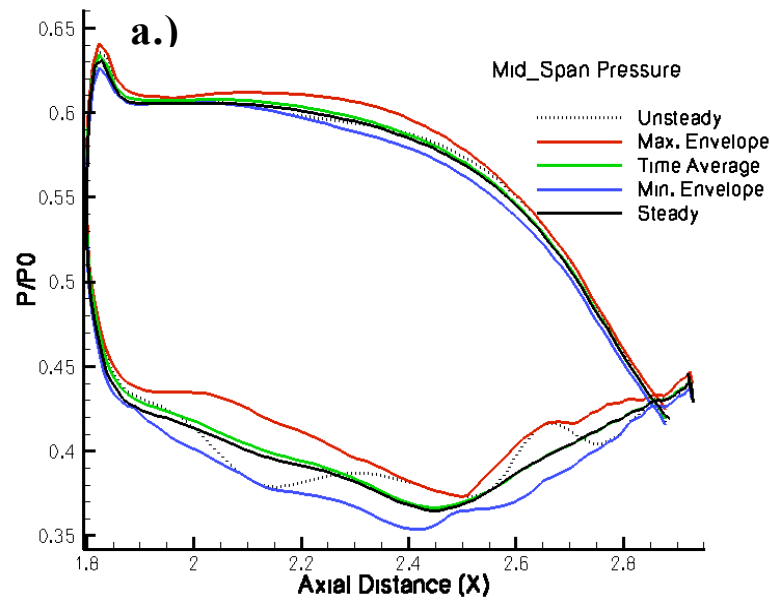

b.)

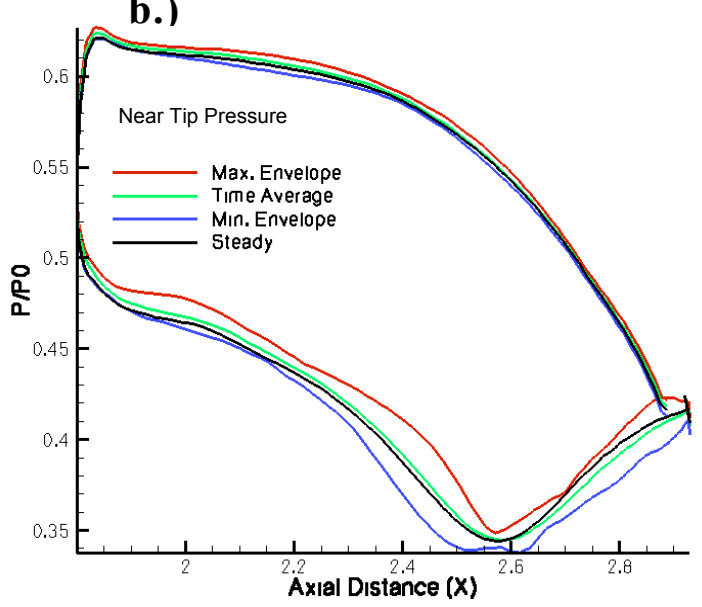

Figure 6- Relative pressure distribution at (a) mid span and (b) $95 \%$ blade span 

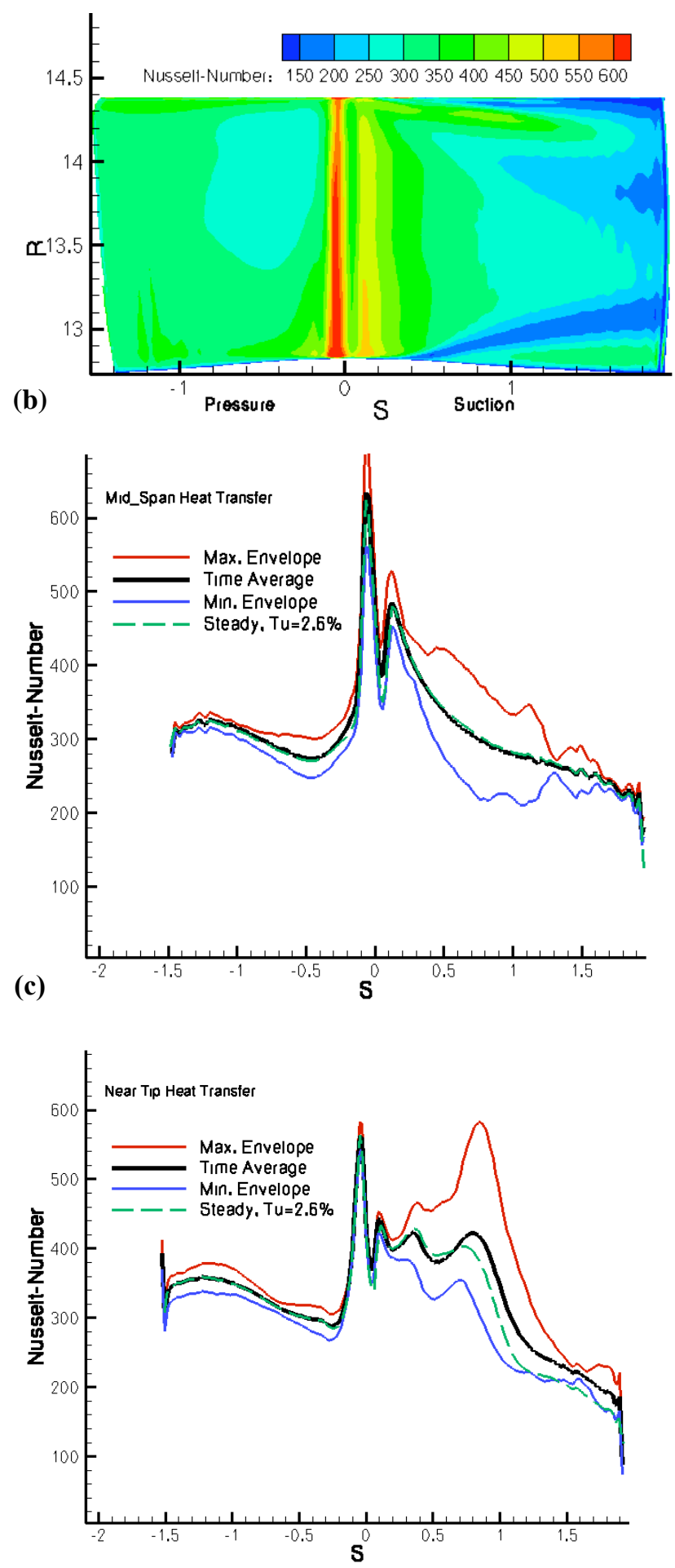

Figure 7- (a) Average Nusselt number on the blade surface, (b) at the mid span and (c) at the $95 \%$ span

purposes. The minor deviation is mainly on the suction side. With the exception of the location just past the leading edge on the suction side near the hub, where the deviation locally is of the order of five percent, the deviation elsewhere on the suction side is limited to within two percent of the steady value. The area for which the percentage deviation is relatively large is in a location for which the local pressure is itself small resulting in

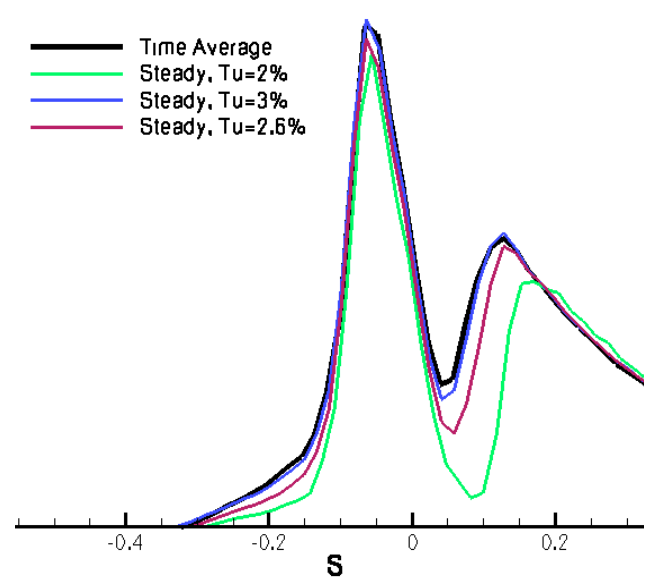

Figure 8- Variation in computed heat transfer in the
vicinity of the leading edge due to transition.

the larger deviation. Fig. 6 shows the pressure distribution over the blade surface for the mid span and at $95 \%$ span. The figure is provided to further illustrate the unsteady variation in the pressure, the unsteady pressure envelope, the mean, and finally the steady values of pressure over the blade.

\section{Heat Transfer}

Figure $7 \mathrm{a}$ shows the time averaged Nusselt number on the isothermal blade surface. The abscissa is the wetted distance as measured from the leading edge geometric stagnation point with the suction side represented as positive and pressure side represented as negative. The ordinate is the radial distance from the hub. The Nusselt number, as defined here, is a direct representation of the wall heat flux. Areas with elevated heat transfer are in the vicinity of the leading edge and near the tip as a result of the scrubbing of the tip vortex. The path of the horseshoe/secondary flow vortices on the suction side near the hub is also apparent from the figure.

Figures $7 \mathrm{~b}$ and $7 \mathrm{c}$ show line plots of Nusselt number along the mid span and 95\% span. Also, plotted is the unsteady envelope associated with unsteady heat transfer. The unsteady envelope as can be seen is quite wide. In the near tip area the envelope is even wider than at the midspan. Figure $7 \mathrm{~b}$ also shows the time average heat transfer in the midspan region. In addition the steady heat transfer for the equivalent steady condition $(\mathrm{Tu}=2.6 \%)$ is also reproduced.

Figure 8 shows the variation of heat transfer in the vicinity of the leading edge corresponding to the time average heat transfer and steady conditions with $\mathrm{Tu}=2 . \%$ corresponding to the background intensity, $\mathrm{Tu}=2.6 \%$ which is the equivalent steady condition and a higher level of $3 \%$. As it can be seen, the main effect of increasing the inlet turbulence intensity is to hasten the transition on the suction side. The $3 \%$ level which is somewhat larger than the equivalent steady condition matches the time average heat transfer very well. Dullenkopf and Mayle [12] suggested a model by which the effect of the passing wake on the transition can be included in steady computations of the flow and heat transfer. This was implemented by Ameri and Arnone [13] by superimposing the intermittencies computed 
using the background turbulence intensity and the maximum turbulence intensity in the incoming wake. The steady computations done here do not use the intermittency method.

The percent deviation of the steady from the time averaged heat transfer is plotted in 9 (a) for $\mathrm{Tu}=2.6 \%$ and in 9 (b) for $\mathrm{Tu}=3 \%$. The difference is normalized by the time average heat transfer rates. The differences between the unsteady and steady computations are the same for the 2.6 and $3 \%$ turbulence intensities outside the apparent influence of the leading edge transition. This difference is of the order of $10-15 \%$ near the leading edge for the equivalent steady condition $(\mathrm{Tu}=2.6 \%)$. It is observed that the unsteady mean is within two percent of the steady value over most of the blade surface. This is certainly true of most of the pressure surface with the exception of the area near the hub for the 3\% Tu case. The other two areas of appreciable deviation of time averaged from steady on the blade surface are within the hub secondary flow regime and the tip vortex flows on the suction side. In the near hub region the percent deviations are as much as 16 to $20 \%$ above or below the steady values. It can be argued that the deviations do not represent an overall increase or decrease in the rate of heat transfer and is merely a shift of local maximum or a minimum. Figure 9(c) shows that such an argument is only partially true. In the near hub at $\mathrm{S}=1.8 \mathrm{Cx}$ there appears to be a shift, but in the near tip region there is a net increase in heat transfer. This increase is in the range of $8-20 \%$ as shown in Fig. 9(a) and 9 (b). Not all the positive differences are accompanied by a negative difference. The areas of increased heat transfer tend to match the areas of negative pressure deviation of Fig. 5(b) and thus a positive change in average unsteady velocity over the steady. If borne out by further evidence, the heat transfer rate difference, in the near tip region, may need to be either modeled and added to steady computational results or computed outright. It is interesting that the area of positive deviation of heat transfer in the near tip region is in an area where blades fail due to high rate of heat transfer and difficulty to cool.

\section{BLADE TIP}

\section{Pressure Distribution}

Figures 10(a) and 10(b) show the time average blade tip pressure and the percent deviation from the average of the steady, respectively. The blade tip pressure is higher than the steady value in the front half of the blade and lower in the trailing half of the blade. But, the differences are all within $2 \%$ of the average pressure.

\section{Heat Transfer}

Figures 11(a) and 11(b) show the average blade tip Nusselt number and percent deviation of the steady Nusselt number thereof, respectively. Referring to these figures, the variation in the heat transfer deviation is to within $2 \%$ of the unsteady mean. As such there does not appear to be a very compelling reason to perform an unsteady computation to obtain the tip heat transfer.

\section{SUMMARY AND CONCLUSIONS}

Rotor blade surface and tip pressure distribution and heat transfer were computed as influenced by the upstream vane wake. The wake was simulated using a gust type boundary (a)

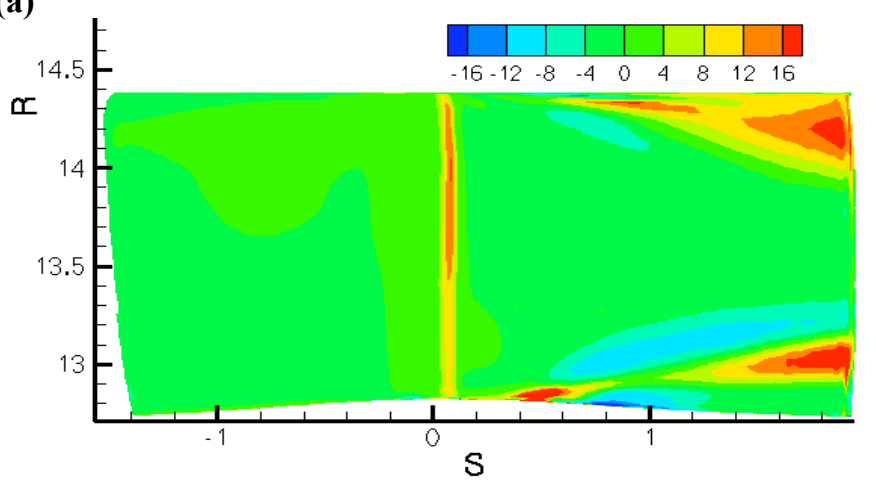

(b)

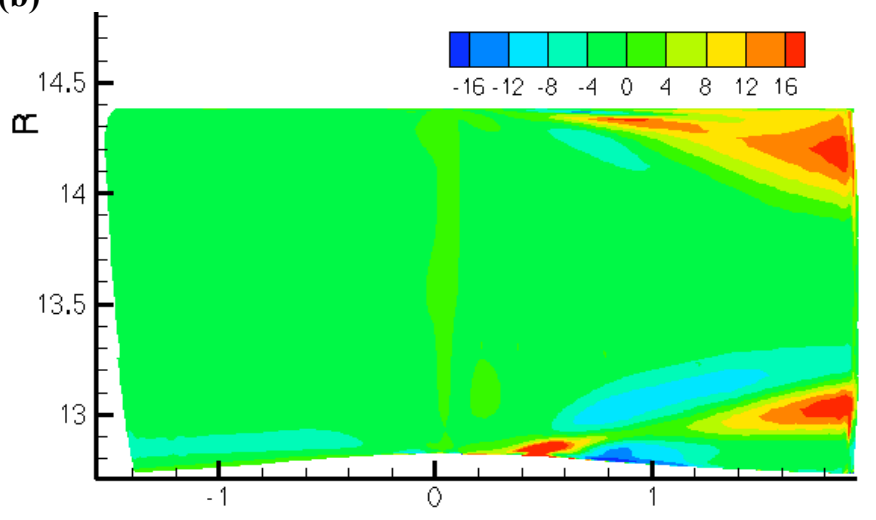

(c)

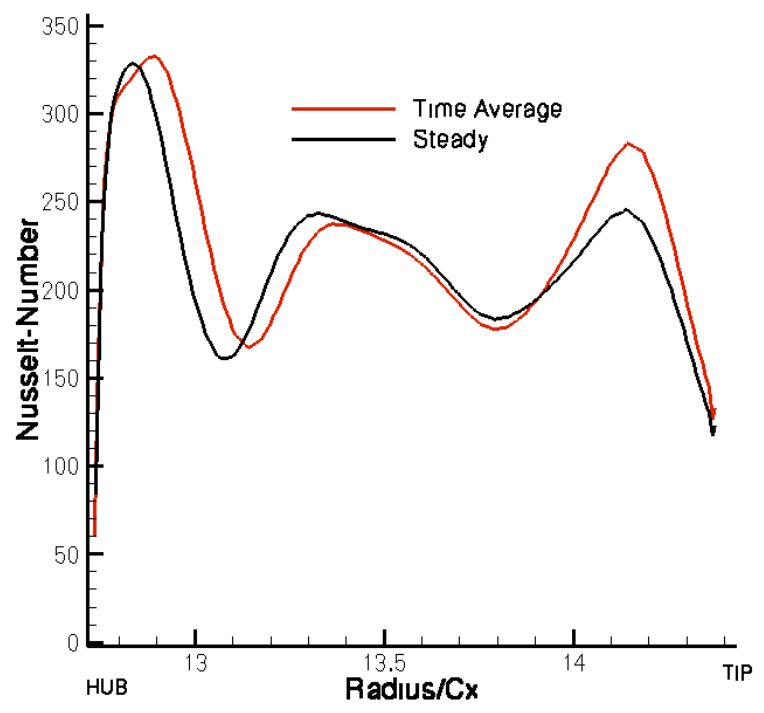

Figure 9- percent deviation of the average heat transfer from the steady computed with (a) $\mathbf{T u}=\mathbf{2 . 6 \%}$ and (b) $\mathrm{Tu}=3 \%$ and (c) comparison of heat transfer at $\mathrm{S}=1.8 \mathrm{Cx}$ across the blade suction surface

condition. The tip clearance used was $2.0 \%$ of span as used in earlier computations [7,9]. A single blade with a periodic boundary condition was simulated. As the periodicity requirement calls for 46 vane wakes for 76 blades, the present simplification was found to provide time average results that were quite close to those obtained using near true periodicity thus making the computations relevant to the 46:76 ratio. As for 
a.)

b.)
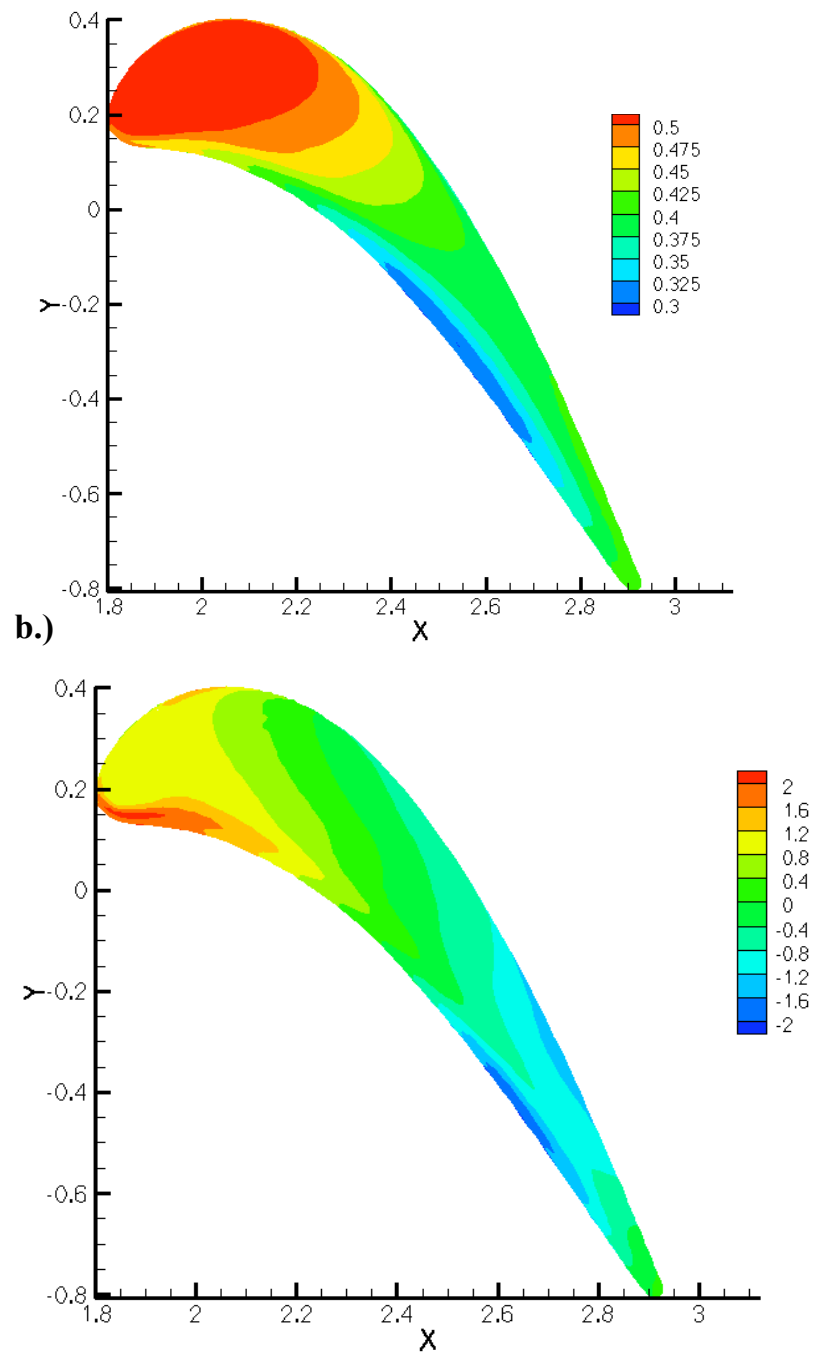

Figure 10(a) Pressure distribution on the blade tip (b) percent deviation of the time average of pressure from the steady equivalent solution

the difference between the time mean values and steady values of local heat transfer, the analyses were done carefully to ensure matching of the average inlet total pressures between the two cases. The computations were simplified and, as such, there were no variations in the inlet total temperature, such as those due to vane cooling or hot streaks. Also, the secondary flows due to upstream vane were not modeled.

It was found that there is a significant difference on the blade surface for the heat transfer but a small difference on the blade tip. Steady computation was found to underestimate the blade heat transfer near the tip on the suction side. So far as the tip heat transfer is concerned, our computations did not show a significant difference between the unsteady mean and steady heat transfer and hence no compelling reason for performing an unsteady computation to obtain the tip heat transfer was found.

Further numerical experiments are needed to ensure generality of the present conclusions. It bears repeating that the present computations are simplified and do not include all the complicating effects.
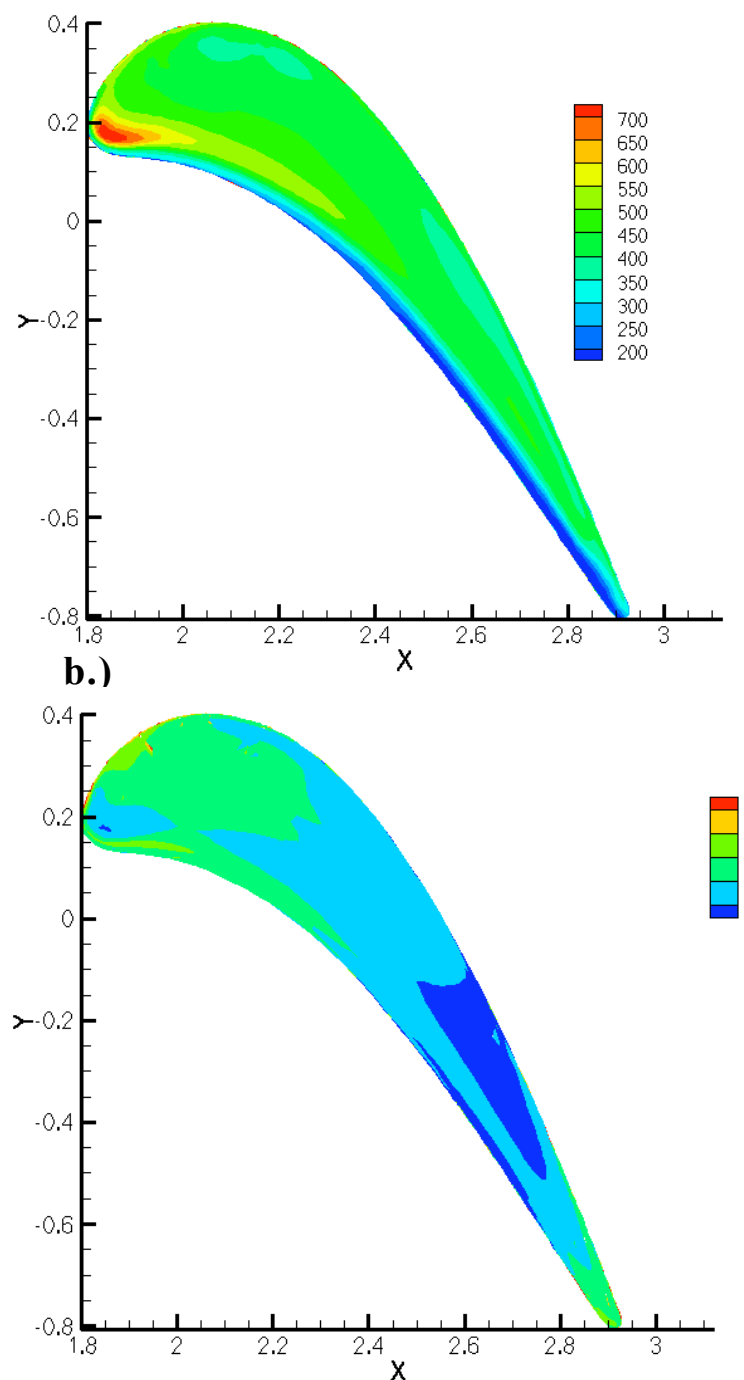

Figure 11(a) Heat transfer distribution on the blade tip and (b) percent deviation of the time average of heat transfer from the steady equivalent solution

\section{REFERENCES}

[1] Rao, K. V. ; Delaney, R. A. and Dunn, M. G., "Vane-Blade Interaction in a Transonic Turbine, II-Heat Transfer," Journal of Propulsion and Power 1994, Vol. 10, No. 3 (312-317)

[2] M.G. Dunn, C.W. Haldeman, R.S. Abhari, and M.L. McMillan, "Influence of Vane/Blade Spacing on the Heat Flux for a Transonic Turbine", 2000-GT-0206.

[3] Michelassi, V; Martelli, F.; Deons, R.; Arts, T. and Sieverding, C. H.; "Unsteady Heat Transfer in Stator-Rotor Interaction by Two-Equation Turbulence Mode," Journal of Turbomachinery Vol. 121, July 1999. pp 436-447.

[4] Abhari, R. S.; Guenette, G. R.; Epstein, A. H. and Giles, M. B., "Comparison of Time-Resolved Turbine Rotor Blade Heat Transfer Measurements and Numerical Calculations," Journal of Turbomachinery, Vol. 114, October 1992. pp. 818-827.

[5] Ameri, A. A., Rigby, D., Heidmann, J. Steinthorsson, E., Fabian, J. , "Effects of Unsteadiness Due to Wake Passing on Rotor Blade Heat Transfer," AIAA-2006-3263 
[6] Wilcox, D. C., 1994, Turbulence Modeling for CFD, DCW Industries, Inc., La Canada, CA.

[7] Ameri, A. A., E. Steinthorsson, D. Rigby, 1998, "Effect of Squealer Tips on Rotor Heat Transfer and Efficiency," ASME Journal of Turbomachinery, 120, No. 4., pp. 753-759

[8] Halila, E. E. and Lenahan, D. T., and Thomas, L. L., 1982, "Energy Efficient Engine, High Pressure Turbine Test Hardware Detailed Design Report," NASA CR-167955.

[9] Ameri, A. A., E. Steinthorsson, D. Rigby, "Effect of Tip Clearance and Casing Recess on Heat Transfer and Stage Efficiency in Axial Turbines," ASME Journal of Turbomachinery, 121, No. 4, pp 683-693, October 1999.

[10] Ameri, A. A. and Bunker, R. S., 2000, "Heat Transfer and Flow in the First Stage Blade Tip of a Power Generation Gas
Turbine, Part 2: Analytical Results, ASME Journal of Turbomachinery, 122,, pp. 272-277.

[11] Ali. A. Ameri, "Heat Transfer and Flow on the Blade Tip of a gas Turbine Equipped with a Mean-Camberline Strip," ASME Journal of Turbomachinery, 123, No. 4. pp. 704-708, October 2001.

[12] Dullenkopf, M., and Mayle, R. E., 1994. "The Effect of Incidence Turbulence and Moving Wakes on Laminar Heat Transfer in Gas Turbines," Journal of Turbomachinery, Vol. 116, pp. 23-28.

[13] Ameri A. A. and Arnone A. "Transition Modeling Effects on Turbine Rotor Blade Heat Transfer Prediction," Journal of Turbomachinery, Vol. 118, April 1996, pp. 307-317 


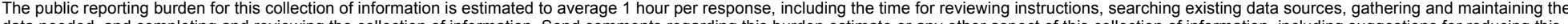

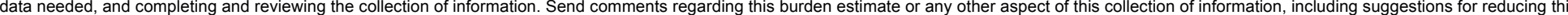

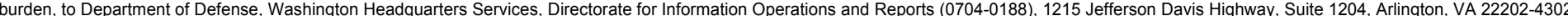

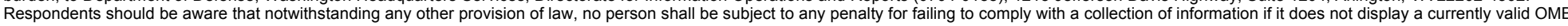
control number.

PLEASE DO NOT RETURN YOUR FORM TO THE ABOVE ADDRESS.

\section{REPORT DATE (DD-MM-YYYY) \\ 2. REPORT TYPE \\ 3. DATES COVERED (From - To)}

01-09-2007

Technical Memorandum

\section{TITLE AND SUBTITLE}

Unsteady Turbine Blade and Tip Heat Transfer Due to Wake Passing

5b. GRANT NUMBER

5c. PROGRAM ELEMENT NUMBER

6. AUTHOR(S)

Ameri, Ali, A.; Rigby, David, L.; Steinthorsson, Erlendur; Heidmann, James; Fabian, John, C.

\section{5d. PROJECT NUMBER}

5e. TASK NUMBER

5f. WORK UNIT NUMBER

WBS 984754.02.07.03.16.06

\section{PERFORMING ORGANIZATION} REPORT NUMBER

E-16116

National Aeronautics and Space Administration

John H. Glenn Research Center at Lewis Field

Cleveland, Ohio 44135-3191

\section{SPONSORING/MONITORING AGENCY NAME(S) AND ADDRESS(ES)}

National Aeronautics and Space Administration

Washington, DC 20546-0001

10. SPONSORING/MONITORS
ACRONYM(S)
NASA
11. SPONSORING/MONITORING
REPORT NUMBER
NASA/TM-2007-214942

\section{DISTRIBUTION/AVAILABILITY STATEMENT}

Unclassified-Unlimited

Subject Categories: 07 and 02

Available electronically at http://gltrs.grc.nasa.gov

This publication is available from the NASA Center for AeroSpace Information, 301-621-0390

\section{SUPPLEMENTARY NOTES}

\section{ABSTRACT}

The geometry and the flow conditions of the first stage turbine blade of GE's E3 engine have been used to obtain the unsteady threedimensional blade and tip heat transfer. The isothermal wall boundary condition was used. The effect of the upstream wake of the first stage vane was of interest and was simulated by provision of a "gust" type boundary condition upstream of the blades. A one blade periodic domain was used. The consequence of this choice was explored in a preliminary study which showed little difference in the time mean heat transfer between 1:1 and 2:3 vane/blade domains. The full three-dimensional computations are of the blade having a clearance gap of 2 percent the span. Comparison between the time averaged unsteady and steady heat transfer is provided. It is shown that there is a significant difference between the steady and time mean of unsteady blade heat transfer in localized regions. The differences on the suction side of the blade in the near hub and near tip regions were found to be rather significant. Steady analysis underestimated the blade heat transfer by as much as 20 percent as compared to the time average obtained from the unsteady analysis. As for the blade tip, the steady analysis and the unsteady analysis gave results to within 2 percent.

\section{SUBJECT TERMS}

Turbine; Heat transfer; Blade; Unsteady flows

\section{SECURITY CLASSIFICATION OF:}

a. REPORT

$\mathrm{U}$

\section{b. ABSTRACT}

U

17. LIMITATION OF
ABSTRACT
UU

\section{NUMBER \\ OF \\ PAGES}

15 19a. NAME OF RESPONSIBLE PERSON

STI Help Desk (email:help@sti.nasa.gov)

19b. TELEPHONE NUMBER (include area code) $301-621-0390$ 

